\title{
Electrochemical and Mechanical Properties of Sodium-Ion Conducting Cross-Linked Polymer Gel Electrolyte
}

\author{
Yuan Xue ${ }^{1, *}$, Xiang Li' ${ }^{2}$, David J. Quesnel ${ }^{1}$ \\ ${ }^{1}$ Materials Science Program and Mechanical Engineering Department, University of Rochester, \\ Rochester NY 14627, USA, \\ ${ }^{2}$ Microsystems Engineering Program and Chemical Engineering Department, Rochester Institute of \\ Technology, Rochester, NY 14623, USA, \\ *E-mail: yxue4@ur.rochester.edu
}

doi: $10.20964 / 2017.11 .56$

Received: 27 July 2017 / Accepted: 6 September 2017 / Published: 12 October 2017

The free radical polymerization of cross-linked poly(methyl methacrylate) (PMMA) polymer gel electrolyte (PGE) for sodium-ion transport exhibits high ionic conductivity, good mechanical property and low cost. Appropriate amounts of sodium hexafluorophosphate $\left(\mathrm{NaPF}_{6}\right)$ were arbitrarily added into cross-linked PGEs in order to decrease the crystallinity of the polymer and to provide more charge carriers to facilitate ionic conductivity. The Shore A durometer test revealed that the $\mathrm{NaPF}_{6}$ addition also enhanced the hardness of the cross-linked PGEs. The highest ionic conductivity obtained was $1.33 \times 10^{-3} \mathrm{~S} \mathrm{~cm}^{-1}$ for the cross-linked PGE with $20 \mathrm{wt} . \% \mathrm{NaPF}_{6}$. Activation energies calculated based on Arrhenius behavior for cross-linked PGEs with $10 \mathrm{wt} . \%, 20 \mathrm{wt} \%$ and $30 \mathrm{wt} . \% \mathrm{NaPF}_{6}$ additions were $0.13,0.10$ and $0.16 \mathrm{eV}$, respectively. The electrochemical window was from $-2.5 \mathrm{~V}$ to $2.5 \mathrm{~V}$ and the transference numbers was ranging from 0.9 to 0.96 . This work demonstrates that the adoption of cross-linking technique and $\mathrm{NaPF}_{6}$ opens the door to facile synthesis of sodium ion conductive PGEs, in which the mechanical property and electrochemical behavior are easy to be tailored by simply tuning $\mathrm{NaPF}_{6}$ additives. The enhancement of hardness and ionic conductivity of cross-linked PGEs enable their potential applications in advanced energy storage systems.

Keywords: Polymer gel electrolyte; Electrochemistry; Cross-linked poly(methyl methacrylate); Sodium hexafluorophosphate; Sodium ion conducting

\section{$\underline{\text { FULL TEXT }}$}

(C) 2017 The Authors. Published by ESG (www.electrochemsci.org). This article is an open access article distributed under the terms and conditions of the Creative Commons Attribution license (http://creativecommons.org/licenses/by/4.0/). 